\title{
Gastrointestinal stromal tumor: 15-years' experience in a single center
}

\author{
Ming Wang ${ }^{1}$, Jia Xu¹, Yun Zhang ${ }^{1}$, Lin Tu', Wei-Qing Qiu', Chao-Jie Wang ${ }^{1}$, Yan-Ying Shen², Qiang Liu² \\ and Hui $\mathrm{CaO}^{1 *}$
}

\begin{abstract}
Background: Gastrointestinal stromal tumor (GIST) is known for its wide variability in biological behaviors and it is difficult to predict its malignant potential. The aim of this study is to explore the characteristics and prognostic factors of GIST.

Methods: Clinical and pathological data of 497 GIST patients in our center between 1997 and 2012 were reviewed.

Results: Patients were categorized into very low-, low-, intermediate- and high-risk groups according to modified National Institutes of Health $(\mathrm{NIH})$ consensus classification system. Among the 401 patients untreated with imatinib mesylate (IM), 5-year overall survival (OS) in very low-, low-, intermediate- and high-risk groups was 100\%, 100\%, 89.6\% and 65.9\%; and 5-year relapse-free survival (RFS) was 100\%, 98.1\%, 90.9\% and 44.5\%, respectively. Univariate analysis revealed that sex, tumor size, mitotic rate, risk grade, CD34 expression, and adjacent involvement were predictors of OS or RFS. COX hazard proportional model (Forward LR) showed that large tumor size, high mitotic rate, and high risk grade were independent risk factors to OS, whereas high mitotic rate, high risk grade and adjacent organ involvement were independent risk factors to RFS. The intermediate-high risk patients who received IM adjuvant therapy $(n=87)$ had better 5 -year OS and RFS than those who did not ( $n=188)(94.9 \%$ vs. $72.1 ; 82.3 \%$ vs. $56.3 \%$, respectively). Similarly, advanced GIST patients underwent IM therapy $(n=45)$ had better 3-year OS and 1-year progression-free survival (PFS) than those who didn't ( $n=42)(75.6 \%$ vs. $6.8 \% ; 87.6 \%$ vs. $12.4 \%$, respectively).
\end{abstract}

Conclusions: Very low- and low-risk GISTs can be treated with surgery alone. Large tumor size, high mitotic rate, high risk grade, and adjacent organ involvement contribute to the poor outcome. IM therapy significantly improves the survival of intermediate-high risk or advanced GIST patients.

Keywords: Gastrointestinal stromal tumor, Survival, Imatinib

\section{Background}

Gastrointestinal stromal tumor (GIST) is the most common mesenchymal neoplasm in the gastrointestinal (GI) tract [1]. Mazur and Clark [2] first introduced the concept of "stromal tumor" in 1983. Advance in pathology, immunohistochemistry and molecular biology in recent years has greatly improved the diagnosis of GIST. It is now considered that GISTs arise from interstitial Cajal cells (ICCs), expressing CD117 (product of c-kit proto-oncogene), and harboring c-kit or platelet-derived growth factor receptor alpha (PDGFRA) gain-of-function mutation [3-5].

\footnotetext{
* Correspondence: caohuishcn@hotmail.com

'Department of General Surgery, Ren Ji Hospital, School of Medicine, Shanghai Jiao Tong University, Floor 11, Building 7, NO. 1630, Dongfang Road, Shanghai 200127, China

Full list of author information is available at the end of the article
}

GIST is known for its wide variability in biological behaviors and it is difficult to predict its malignant potential $[6,7]$. Tumor size, mitotic rate and tumor site are considered as the most important prognostic parameters for patients after surgery [8]. However, neither small size nor low mitotic rate could exclude malignant potential [9]. On the other hand, some enormous tumor with high mitotic rate could also achieve long-term survival, even without adjuvant therapy [10]. The post-operation outcome of GIST is highly variable, with 5-year survival rate ranging from $48 \%$ to $80 \%$ $[11,12]$. The variability is mainly due to the introduction of a tyrosine kinases inhibitor (TKI), imatinib mesylate, which was used in metastatic/recurrent GISTs since 2000 
and had been proved as an adjuvant therapy several years ago $[13,14]$.

The purpose of this study is to share our latest 15 years of experience and to explore the prognostic factors of GISTs.

\section{Methods}

The clinicopathological and follow-up data of 497 operable GIST patients admitted to Department of General Surgery, Ren Ji Hospital, School of Medicine, Shanghai Jiao Tong University between 1997 and 2012 were reviewed. Each diagnosis of "GIST" was confirmed by postoperative histopathology and immunohistochemistry assay (IHCA). The results of histopathological features and IHCA findings of every case were reviewed by 2 experienced pathologists. Those diagnosed as "gastrointestinal stromal mesenchymal tumor" prior to 2000 were re-examined by IHCA to confirm the diagnosis of GIST. The tumors were categorized into very low, low, intermediate and high risk groups according to the modified NIH risk classification criteria [7] (Table 1). Only the cases with complete medical records and pathological data were involved in present study. The following parameters were reviewed and analyzed: age, sex, clinical presentation, surgical detail, tumor site, tumor size, mitotic rate, IHCA (CD117, CD34, vimentin, smooth muscle actin (SMA), S-100, Discovered On GIST 1 (DOG1)), TKI therapy and outcome. Survival outcome in terms of overall survival (OS), relapse-free survival (RFS), and progression-free survival (PFS) were assessed. OS was defined as the period from surgery to the last follow-up or death. RFS was defined as the period from surgery to the time of clinical or radiological evidence of disease relapse. PFS in patients who had metastatic or recurrent disease was defined as the period from the time when relapse

Table 1 Risk classification of GISTs

\begin{tabular}{lccc}
\hline Risk classification & $\begin{array}{c}\text { Tumor } \\
\text { size }(\mathbf{c m})\end{array}$ & $\begin{array}{c}\text { Mitotic rate } \\
\text { per 50 HPF }\end{array}$ & Tumor site \\
\hline Very low risk & $<2$ & $<=5$ & Any \\
Low risk & $2.1-5.0$ & $<=5$ & Any \\
Intermediate risk & $2.1-5.0$ & $>5$ & Gastric \\
& $<5$ & $6-10$ & Any \\
High risk & $5.1-10$ & $<=5$ & Gastric \\
& Any & Any & Tumor rupture \\
& $>10$ & Any & Any \\
& Any & $>10$ & Any \\
& $>5$ & $>5$ & Any \\
& $2.1-5.0$ & $>5$ & Non gastric \\
& $5.1-10.0$ & $<=5$ & Non gastric \\
\hline
\end{tabular}

HPF = high power field. was diagnosed to clinical or radiological evidence of progression or death.

All patients provided written informed consent for their information to be stored in the hospital database, and we obtained separate consent for use of research. Study approval was obtained from independent ethics committees from Ren Ji Hospital, School of Medicine, Shanghai Jiao Tong University. The study was undertaken in accordance with the ethical standards of the World Medical Association Declaration of Helsinki.

$x^{2}$ test and Fisher's exact test were performed to analyze qualitative parameters and Kaplan-Meier method with log rank test was used for postoperative survival analysis. Independent factors were identified in multivariate analysis by COX proportional hazard analysis with forward selection at $\mathrm{P}<0.05$. Odds ratios (ORs) and $95 \%$ confidence intervals (CIs) were determined using unconditional multiple logistic regression models. Two-sided $\mathrm{P}$ values of 0.05 or less were considered to indicate statistical significance.

\section{Results}

The incidence of GIST ranges from 11 to 15 per million per year [15-18]. Growing evidence indicates the incidence is considerably underestimated $[19,20]$. The number of GIST patients admitted to our center is on the rise. In the past two year, it has approached 100 cases a year (Figure 1).

\section{Clinical and pathological characteristics}

Total 497 GIST patients were involved in present study, with a median age of 60 years (range 23-90) and 55.9\% was male. Stomach and small bowel were the most common sites of primary disease $(59.0 \%$ and $22.5 \%$, respectively). The most common clinical presentation was abdominal discomfort, followed by GI bleeding. Distribution of risk groups: $8.0 \%$, very low; $36.4 \%$, low; $15.7 \%$, intermediate; and $39.8 \%$, high risk. IM adjuvant therapy was given to 96 of the patients to prevent disease relapse. Recurrence or metastases were observed in 89 patients during the follow-up period. Among which, IM was used to control disease in 46 patients.

Of all the cases, $87.3 \%$ was CD117 (+); 80.3\%, CD34 (+); $23.6 \%$, SMA (+); and 21.5\%, S-100 (+). DOG1 was a newly developed IHCA marker, which was positive in 139 out of 149 cases (93.3\%). The diagnosis of GIST in patients presented as both CD117 and DOG1 negative was confirmed by detection of mutation in c-kit/PDGFRA gene. Their clinical and pathological characteristics are listed in Table 2.

Lymph node metastasis was detected in 5 out of 497 cases (1.01\%); clinical and pathological characteristics of these 5 cases were described in Table 3.

Survival analysis on patients without IM adjuvant therapy Given the fact that imatinib is an effective drug on GIST, the first survival analysis was based on the population of 


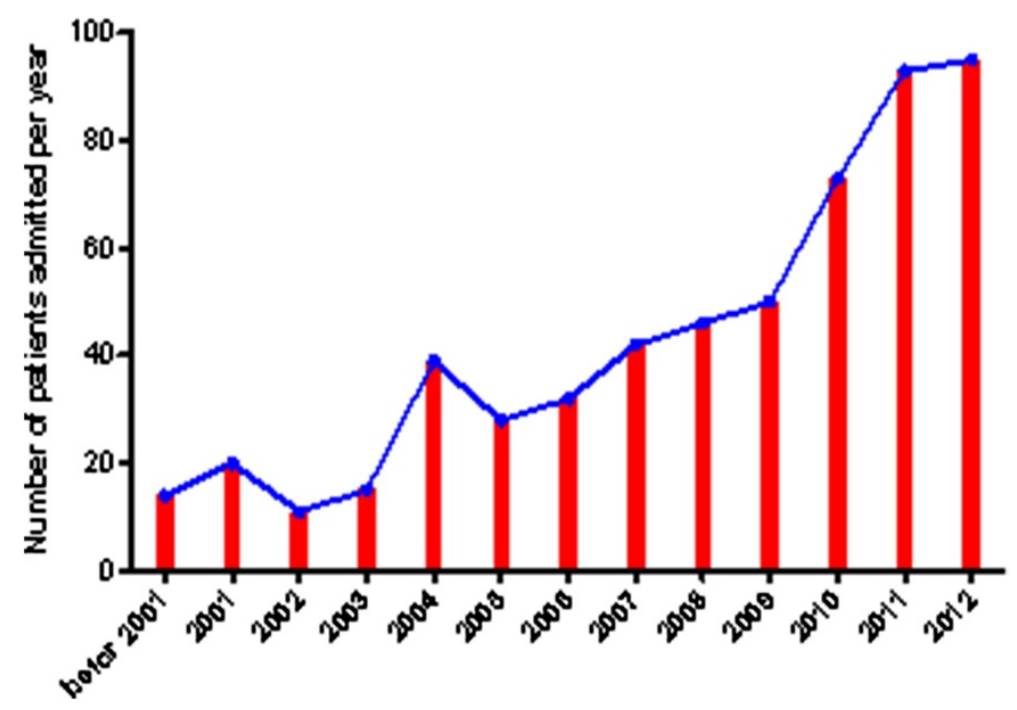

Figure 1 Annual number of newly admitted GIST patient since 1997.

patients who were not given IM adjuvant therapy. Therefore, 401 patients with operable GIST were enrolled in the cohort, with a median duration of 50 months (range, 7-187 months). Recurrence or metastasis occurred in 79 patients (19.7\%). The abdominopelvic cavity was the most common site of metastases (51 cases), followed by liver (22 cases), lung (3 cases), vertebral column (1 case), umbilicus (1 case), and fossa axillaris ( 1 case). Forty-five patients died of GIST progression, and 4 died of other diseases. The 1-, 3-, 5-year OS of 401 GISTs was $97.7 \%, 92.6 \%$ and $84.8 \%$, respectively; The 1-, 3-, 5-year RFS was 93.2\%, $82.1 \%$ and $77.4 \%$, respectively.

The 1-, 3-, 5-year OS according to risk grade was: 100\%, $100 \%, 100 \%$ (very low risk); 100\%, 100\%, 100\% (low risk); $100 \%, 97.8 \%$, 89.6\% (intermediated risk); 93.5\%, 80.8\%, $65.9 \%$ (high risk), respectively (Figure 2).

The 1-, 3-, 5-year RFS according to risk group was: $100 \%, 100 \%, 100 \%$ (very low risk); $100 \%, 100 \%, 98.1 \%$ (low risk); 100\%, 93.8\%, 90.9\% (intermediated risk); 80.6\%, $53.1 \%, 44.5 \%$ (high risk), respectively (Figure 3).

Univariate analysis revealed that male gender, nongastric origin, larger tumor size, higher mitotic rate, higher risk grade, CD34 negative expression, and adjacent organ involvement contributed to poorer outcome (lower OS and RFS), whereas age and expression of CD117, SMA, and S-100 were not associated with prognosis (see Table 4 and Additional files 1 and 2).

Multivariate analysis by Cox proportional hazards regression (Forward LR) model indicated that tumor size, mitotic rate, and risk grade were independent risk factors to OS for GISTs, and that mitotic rate, risk grade, and adjacent involvement were independent risk factors to RFS (Tables 5 and 6).

\section{Survival analysis of patients received IM therapy}

From 2007 to 2012, 87 patients with intermediate-high risk GIST received IM adjuvant therapy after radical resection (Adjuvant group). Compared with those patients who were with same risk GIST (intermediate-high risk) while were not given IM adjuvant therapy (Non-adjuvant group, $\mathrm{n}=188$ ), adjuvant group had better 5 -year RFS $(82.3 \%$ vs. $56.3 \%, \mathrm{P}<0.001)$ and 5 -year OS $(94.9 \%$ vs. $72.1 \%, \mathrm{P}=0.001$ ) (Figure 4 ). In addition, there was no statistical difference in other clinicopathological features (sex, age, tumor site, tumor size, mitotic rate, risk grade, etc.) between the two groups (see Additional file 3), indicating that these features had no impact on the effect of IM.

In the cohort, 87 patients developed recurrence of metastasis after surgery for the primary disease. Among them, c-kit/PDGFRA mutation status was screened in 39 patients. Their mutational characteristics were demonstrated in our previous report [21]. Mutations in c-kit exon 11, c-kit exon 9, and PDGFRA exon 18 were identified in 29, 4, and 1 patients, respectively. And the rest 5 GISTs showed c-kit and PDGFRA wild type. Among all the 87 advanced GIST patients, 45 (including 33 c-kit mutant GISTs, 5 wild-type GISTs, and 7 GISTs with unknown mutation type) were treated with IM, and the other 42 didn't undergo any TKI therapy (10 due to personal reasons and the rest were cases prior to 2005). There was significant difference in outcome between the two groups: patients underwent postoperative IM treatment had better 1-, 3-year OS than those untreated with IM (97.6\% and $75.6 \%$ vs. $58.7 \%$ and $6.8 \%$, respectively, $\mathrm{P}<0.001)$. IM therapy also improved 1-year progression-free survival (PFS) of these patients $(87.6 \%$ vs. $12.4 \%, \mathrm{P}<0.001)$ (Figure 5). 


\section{Table 2 Clinical and pathological characteristics of 497 GIST patients}

\begin{tabular}{|c|c|}
\hline \multicolumn{2}{|l|}{ Age (years) } \\
\hline Median & 60 \\
\hline Range & $23-90$ \\
\hline \multicolumn{2}{|l|}{ Sex, n (\%) } \\
\hline Male & $278(55.9)$ \\
\hline Female & $219(44.1)$ \\
\hline \multicolumn{2}{|l|}{ Primary site of tumor, $\mathrm{n}(\%)$} \\
\hline Stomach & $293(59.0)$ \\
\hline Duodenum & $31(6.2)$ \\
\hline Small bowel & $112(22.5)$ \\
\hline Large bowel & $4(0.8)$ \\
\hline Rectum & $21(4.2)$ \\
\hline Esophagus & $3(0.6)$ \\
\hline Other (omentum, mesenterium and retroperitoneum ) & $33(6.6)$ \\
\hline \multicolumn{2}{|l|}{ Clinical manifestation, n (\%) } \\
\hline Abdominal discomfort & $184(37.0)$ \\
\hline Gl bleeding & $142(28.6)$ \\
\hline Diagnosed at physical examination & $81(16.3)$ \\
\hline Abdominal mass & $14(2.8)$ \\
\hline $\begin{array}{l}\text { Other (fever, fatigue, appetite and explored at surgery for } \\
\text { other diseases) }\end{array}$ & $76(15.3)$ \\
\hline \multicolumn{2}{|l|}{ IM therapy } \\
\hline As adjuvant therapy for primary disease & 96 \\
\hline $\begin{array}{l}\text { As therapy for advanced disease (recurrent, metastatic, } \\
\text { unresectable, or incomplete resected) }\end{array}$ & 46 \\
\hline \multicolumn{2}{|l|}{ Immunohistochemistry, n (\%) } \\
\hline CD117 & $434(87.3)$ \\
\hline CD34 & $399(80.3)$ \\
\hline SMA & 119 (23.9) \\
\hline S-100 & 107 (21.5) \\
\hline DOG1 & $139(93.3)^{*}$ \\
\hline
\end{tabular}

*DOG1 was examined in 165 cases.

\section{Discussion}

Although the incidence of GISTs is rising in the oriental population, available document on this area is still limited, especially studies with large sample size in a single center. This study reviewed the clinical and pathological features of 497 GIST cases in Shanghai Ren Ji Hospital to explore the prognostic factors of the disease.

GISTs represent $80 \%$ of mesenchymal tumor of the digestive tract and constitute $5 \%$ of all sarcoma [22]. It had been reported that the annual occurrences of GIST were $11-15$ per million people [15-18]. However, growing evidences have proved that the incidence of GISTs is seriously underestimated. Learn from the studies of Abraham et al. [23] and Agaimy et al. [24], we can draw a conclusion that sub-centimeter GISTs (smaller than 1 $\mathrm{cm}$ ) are common lesions in stomach. Our epidemiologic data show the number of newly diagnosed GISTs is on the fast rise (Figure 1), probably due to the increasing awareness of the disease in clinicians.

Our data indicate that GIST occurrences culminate among people in their 50s and 60s. The youngest GIST patient is a 23-year-old female, who suffered from giant retroperitoneal GIST and died of recurrent disease 32 months after surgery. The oldest patient is a 90-year-old male with intermediate-risk gastric GIST and he was relapse-free at last follow-up, six months after surgery. Although in most published documents there is no clear sex predilection $[3,25,26]$, some studies revealed that there was a slight male predominance [27-29]. Our data agree with the latter.

GISTs have no specific symptom, increasing the difficulty in early diagnosis and treatment. In our data, consistent with the literature, the most frequent complaint is abdominal discomfort, which may or may not be accompanied by GI bleeding [30,31].

GIST may arise anywhere in the GI tract and also in extragastrointestinal locations (extragastrointestinal stromal tumor, EGIST), including omentum, mesenterium, and retroperitoneum [32]. According to our data, the most common GI location of primary disease was stomach (59.0\%), followed by small bowel (22.5\%), duodenum

Table 3 Clinical and pathological characteristics of 5 GIST patients with lymph node metastasis

\begin{tabular}{llllllllll}
\hline Case & Sex & Age & Primary site & Tumor size & $\begin{array}{l}\text { Mitotic rate } \\
\text { per 50HPF }\end{array}$ & MLN/TLN & Mutation & IM therapy & Outcome \\
\hline 1 & M & 60 & S & 8 & 23 & $2 / 4$ & c-kit exon9 & Yes & $\begin{array}{l}\text { Died of disease progression at 33 months } \\
\text { after surgery }\end{array}$ \\
2 & M & 58 & G & 5 & 12 & $1 / 2$ & not available & No & DFS at 101 months after surgery \\
3 & F & 59 & G & 5.5 & $<5$ & $4 / 4$ & c-kit exon11 & Yes & DFS at 45 months after surgery \\
4 & F & 70 & G & 9 & 8 & $1 / 9$ & c-kit exon11 & Yes & DFS at 25 months after surgery \\
5 & M & 31 & D & 18 & $<5$ & $2 / 2$ & c-kit exon11 & Yes & $\begin{array}{l}\text { Survival with residual disease at 3 months } \\
\text { after surgery }\end{array}$ \\
\hline
\end{tabular}

$\mathrm{S}=$ small intestine; $\mathrm{G}$ = stomach; $\mathrm{D}=$ duodenum MLN = metastatic lymph nodes; TLN = total examined lymph nodes; DFS = Disease-free survival. 


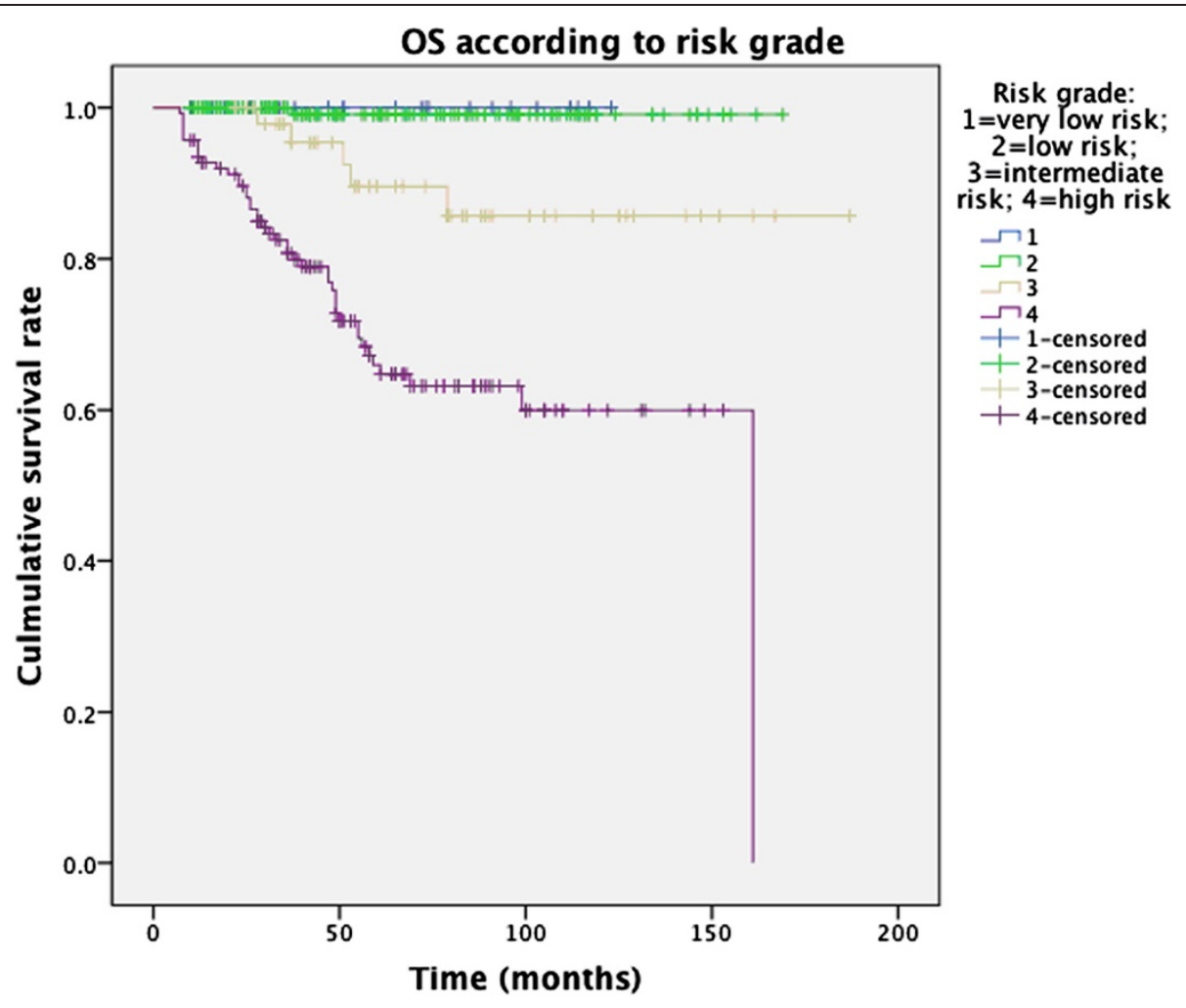

Figure 2 Overall survival in 401 GIST patients according to risk class.

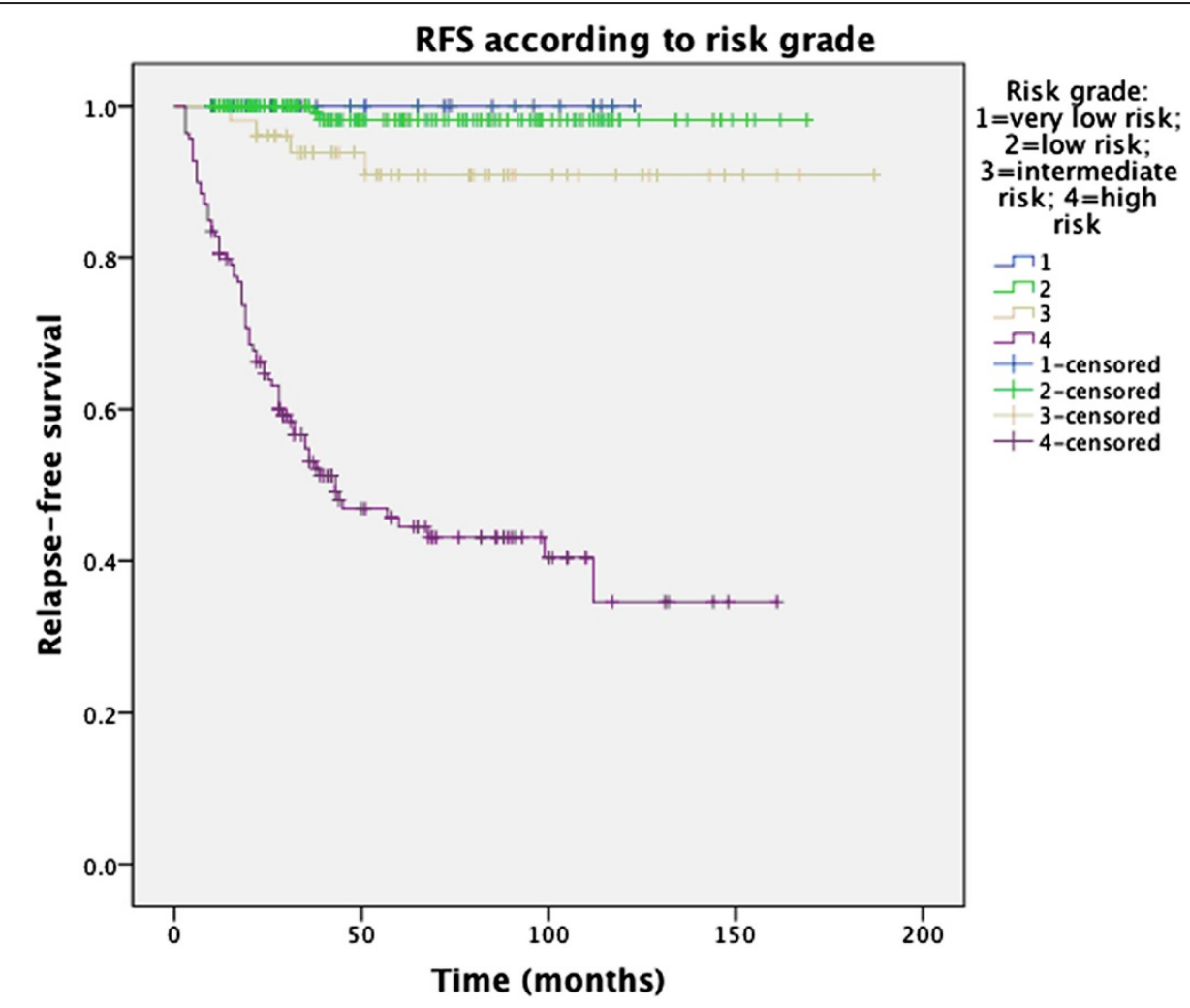

Figure 3 Relapse-free survival in 401 GIST patients according to risk class. 
Table 4 Univariate analysis of OS and RFS in 401 GIST patients

\begin{tabular}{|c|c|c|c|c|c|c|c|c|}
\hline \multirow{2}{*}{$\begin{array}{l}\text { Clinicopathological } \\
\text { feature }\end{array}$} & \multirow[t]{2}{*}{ Group } & \multirow[t]{2}{*}{$N$} & \multicolumn{3}{|l|}{ OS } & \multicolumn{3}{|l|}{ RFS } \\
\hline & & & 5 -year OS (\%) & $x^{2}$ & $\mathrm{P}$-value & 5-year RFS (\%) & $x^{2}$ & P-value \\
\hline \multirow[t]{2}{*}{ Gender } & Male & 221 & 80.2 & 6.590 & 0.010 & 71.6 & 8.914 & 0.003 \\
\hline & Female & 180 & 90.6 & & & 84.4 & & \\
\hline \multirow[t]{2}{*}{ Age } & $<60$ & 197 & 85.7 & 1.573 & 0.210 & 77.4 & 0.011 & 0.917 \\
\hline & $\geq 60$ & 204 & 84.0 & & & 77.4 & & \\
\hline \multirow[t]{2}{*}{ Tumor site } & Gastric & 241 & 86.5 & 1.969 & 0.161 & 86.1 & 18.876 & $<0.001$ \\
\hline & Non-gastric & 160 & 82.5 & & & 65.3 & & \\
\hline \multirow[t]{4}{*}{ Tumor size } & $\leq 2 \mathrm{~cm}$ & 51 & 100 & 110.281 & $<0.001$ & 100 & 146.144 & $<0.001$ \\
\hline & $2.1-5 \mathrm{~cm}$ & 178 & 98.0 & & & 94.6 & & \\
\hline & $5.1-10 \mathrm{~cm}$ & 109 & 80.9 & & & 66.8 & & \\
\hline & $>10 \mathrm{~cm}$ & 63 & 49.2 & & & 33.5 & & \\
\hline \multirow[t]{3}{*}{ Mitotic rate } & $<5 / 50 \mathrm{HPF}$ & 296 & 95.9 & 83.348 & $<0.001$ & 91.2 & 152.472 & $<0.001$ \\
\hline & 5-10/50 HPF & 44 & 68.0 & & & 55.3 & & \\
\hline & $>10 / 50 \mathrm{HPF}$ & 61 & 54.2 & & & 33.7 & & \\
\hline \multirow[t]{4}{*}{ Risk class } & Very low & 39 & 100 & 66.044 & $<0.001$ & 100 & 154.234 & $<0.001$ \\
\hline & Low & 172 & 99.1 & & & 98.1 & & \\
\hline & Intermediate & 51 & 89.6 & & & 90.9 & & \\
\hline & High & 139 & 65.9 & & & 44.5 & & \\
\hline \multirow[t]{2}{*}{ CD117 expression } & Positive & 350 & 83.4 & 3.315 & 0.069 & 76.6 & 1.401 & 0.237 \\
\hline & Negetive & 51 & 95.1 & & & 82.6 & & \\
\hline \multirow[t]{2}{*}{ CD34 expression } & Positive & 322 & 87.2 & 7.564 & 0.006 & 80.6 & 10.777 & 0.001 \\
\hline & Negative & 79 & 75.4 & & & 64.3 & & \\
\hline \multirow[t]{2}{*}{ SMA expression } & Positive & 101 & 90.6 & 1.559 & 0.212 & 83.2 & 2.246 & 0.134 \\
\hline & Negative & 300 & 83.2 & & & 75.6 & & \\
\hline \multirow[t]{2}{*}{ S-100 expression } & Positive & 84 & 88.2 & 1.377 & 0.241 & 74.0 & 0.529 & 0.467 \\
\hline & Negative & 317 & 83.7 & & & 78.5 & & \\
\hline \multirow[t]{2}{*}{ Adjacent involvement } & Without & 336 & 92.1 & 66.176 & $<0.001$ & 87.2 & 147.885 & $<0.001$ \\
\hline & With & 65 & 53.0 & & & 30.8 & & \\
\hline
\end{tabular}

(6.2\%), rectum (4.2\%), large bowel (0.8\%), esophagus $(0.6 \%)$. EGISTs were found in $6.6 \%$ of cases.

Typical GISTs are characterized by positive immunohistochemical (IHC) staining of KIT (CD117), a transmembrane receptor tyrosine kinase. More recently the antigen DOG1 has been incorporated in the IHC panel when CD117 was negative [33]. Our data confirmed the high specificity and sensitivity of this marker: DOG1 expression was seen in 139 of 149 GISTs, including 15 CD117 negative ones.
Except for some sporadic studies [34], lymph node metastasis is reported to be extremely rare in GIST, with incidence ranging from $0 \sim 5 \%$ [11,35-37]. Although lymph node metastasis (LNM) is usually considered as a morphological feature associated with malignancy and poor prognosis [38,39], our data do not support this opinion. Three out of the 5 patients with LNM in this study achieved longer than 2 years' DFS; one of them, though untreated with IM, was still disease-free at the latest follow-up, over 8 years after surgery. This aroused the

Table 5 Multivariate COX regression analysis of OS in 401 GIST patients

\begin{tabular}{ccccc}
\hline Covariate & $\mathrm{X}^{\mathbf{2}}$ & P-value & Hazard ratio & $\mathbf{9 5 \%} \mathrm{Cl}$ \\
\hline Tumor size $(>=10 \mathrm{~cm}$ vs. $<10 \mathrm{~cm})$ & 13.224 & $<0.001$ & 3.293 & $1.732-6.261$ \\
Mitotic rate $(>=5 / 50 \mathrm{HPF}$ vs. $<5 / 50 \mathrm{HPF})$ & 10.619 & 0.001 & 3.841 & $1.710-8.628$ \\
Risk grade (high risk vs. non-high risk) & 4.956 & 0.026 & 3.440 & $1.159-10.207$ \\
\hline
\end{tabular}


Table 6 Multivariate COX regression analysis of RFS in 401 GIST patients

\begin{tabular}{ccccc}
\hline Covariate & $\mathbf{X}^{\mathbf{2}}$ & P-value & $\begin{array}{c}\text { Hazard } \\
\text { ratio }\end{array}$ & $\mathbf{9 5 \% ~ C l}$ \\
\hline $\begin{array}{c}\text { Adjacent involvement } \\
\text { (with vs. without) }\end{array}$ & 11.841 & 0.001 & 2.295 & $1.430-3.683$ \\
$\begin{array}{c}\text { Mitotic rate }(>=5 / 50 \text { HPF } \\
\quad \text { vs. }<5 / 50 \text { HPF) }\end{array}$ & 8.895 & 0.003 & 2.406 & $1.351-4.284$ \\
$\begin{array}{c}\text { Risk grade (high risk vs. } \\
\text { non-high risk) }\end{array}$ & 26.129 & $<0.001$ & 11.794 & $4.579-30.379$ \\
\hline
\end{tabular}

controversy over the exact impact of LNM on GIST outcome. Further studies with larger sample size are required to solve this puzzle. Nonetheless, lymph node dissection should be considered in case of suspected or confirmed LNM.

The distribution of very low-, low-, intermediate-, highrisk groups was $8.0 \%, 36.4 \%, 15.7 \%$, and $39.8 \%$, respectively. Compared to most published literature [28,40,41], the proportion of very low and low risk GIST was much higher. One reason might be the improved screening system and early surgery. In addition, clinical study on minimal invasive procedure (laparoscopic/laparoscopyendoscopy cooperative surgeries) for GIST is being conducted in our center, and offers the opportunity of early operation and further elevated the proportion. Thanks to the popularity of endoscopy, more and more GISTs can be determined at small size. In most cases, having the advantages of small incision and fast recovery, minimal invasive surgery is preferred to traditional open operation.

In our study, the outcome (both OS and RFS) of IM-naive GIST patients was better than that in most published literature $[12,42,43]$ for the same reasons mentioned above (higher proportion of low risk GIST). Nonetheless, the high-risk group still had unsatisfactory results (5-year OS 65.9\%, 5-year RFS 44.5\%, respectively). However, very low- and low-risk GISTs in present study had rather better prognosis: no relapse was found in very low risk group; only one case, a rectal tumor $3.5 \mathrm{~cm}$ in diameter with mitotic rate of $<5 / 50 \mathrm{HPF}$, occurred recurrence in low-risk group.

Prediction of biological behavior of a GIST is essential for selection of candidates for adjuvant therapy as well as determination of the frequency and intensity of postoperative surveillance. However, accurate prediction is often a difficult job. It has been widely accepted that tumor size, mitotic rate, and anatomic site are the most important factors influencing the prognosis of GISTs [8]. These factors form the basis for consensus risk classification. Our study reveals that risk grade and mitotic rate were independent prognostic factors of both OS and RFS, while tumor size and adjacent organ involvement was independent predictor of OS and RFS, respectively. Mitotic rate was described as a vital indicator for GIST staging and consequential choice of surgical and target therapeutic approach $[44,45]$, its value in prognosis prediction was confirmed again in our study. It's worth mentioning that there is a difficulty in reproducibility among examiners when determining the mitotic rate [44]. Therefore, all specimens should be examined by specialized experts to decrease the deviation.

In present study, males had lower survival rate than females (5-yaer OS, $80.2 \%$ vs. 90.6\%, P = 0.010; 5-year RFS, $71.6 \%$ vs. $84.4 \%, P=0.003)$. This finding was in

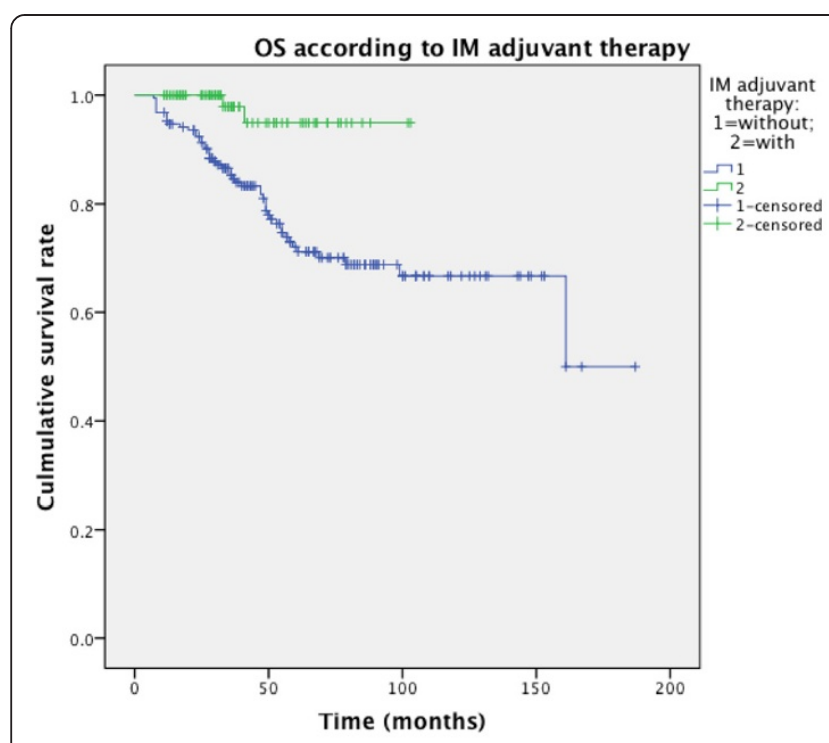

A

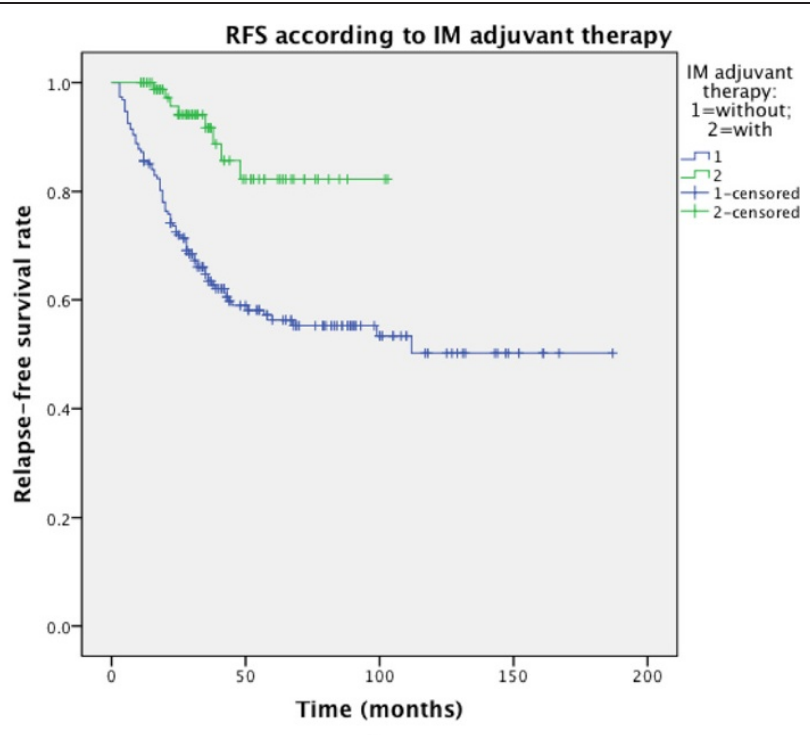

B

Figure 4 Effect of treatment with or without postoperative IM adjuvant therapy on OS and RFS in 275 intermediate-high risk GIST patients (A: overall survival; B: relapse-free survival). 


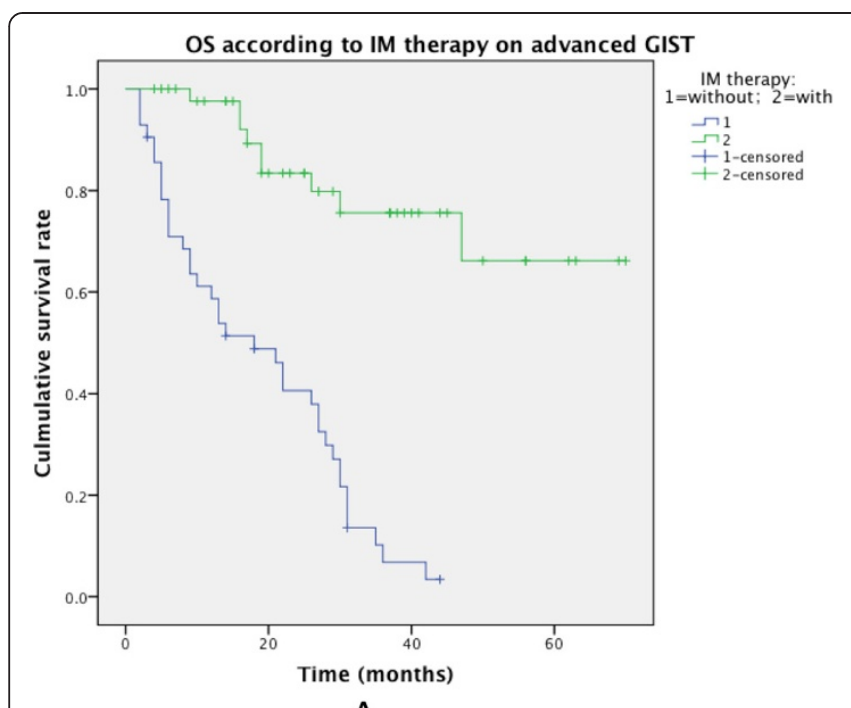

A

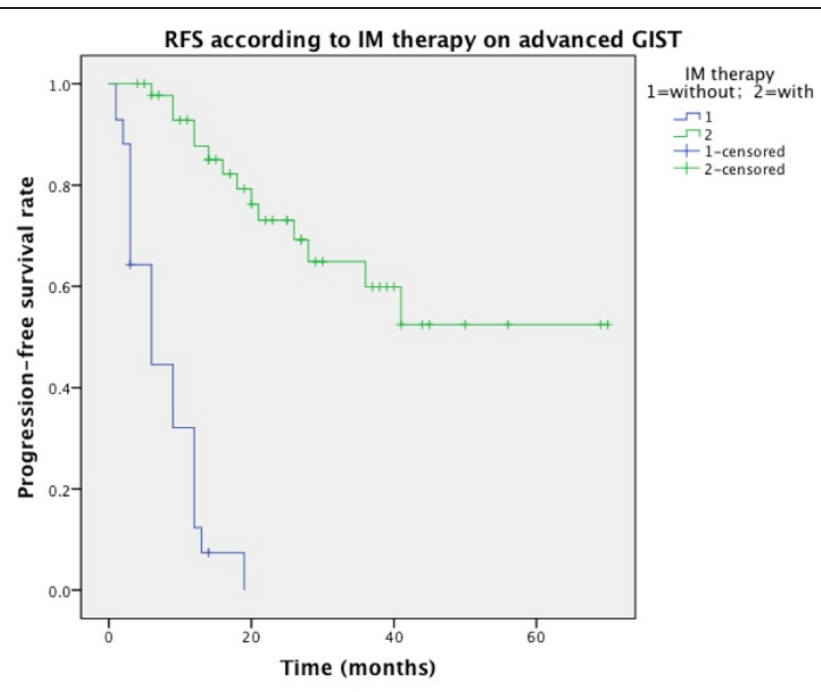

B

Figure 5 Effect of treatment with or without post-operation IM therapy on OS and PFS in 87 advanced GIST cases (A: overall survival; B: progression-free survival).

consistent with other retrospective studies [46-48]. However, no relationship between sex and survival was found in the multivariate analysis.

Most documents, including our previous study on a small cohort, didn't demonstrate correlation between CD34 expression and GIST patients' prognosis [49-51]. However, univariate analysis of present study revealed that CD34 positive GIST patients had better outcome than CD34 negative patients (5-yaer OS, $87.2 \%$ vs. $75.4 \%, \mathrm{P}=0.006$; 5 -year RFS, $80.6 \%$ vs. $64.3 \%, \mathrm{P}=0.001$ ). Yet subsequent multivariate analysis didn't show relationship between CD34 and patients' survival. Therefore, further studies are required to determine the exact impact of sex and CD34 on GIST prognosis.

Long-term monitoring has shown that surgery alone is usually insufficient to control high-risk diseases. Introduction of imatinib has greatly improved the outcome of GIST. In China, the application of IM as adjuvant therapy was widely accepted not earlier than 2005. Presently, IM is standard therapy for advanced and primary intermediate-high risk GISTs (for adjuvant option) [14]. In present study, IM adjuvant therapy had better 5 -year OS and RFS than non-adjuvant group. The limitation of this study is obvious: the selection of candidates and the interval of adjuvant therapy were not standardized. The follow-up period of adjuvant group was much shorter than that of non-adjuvant group, which highlighted the importance of persistent follow-up on those patients. The exact effect of IM on GIST can only be assessed by prospective randomized controlled trials with long-term follow-up, just like Z9001 [52] and SSGXVIII trials [53]. However, our findings still encourage the use of IM adjuvant therapy.
Undoubtedly, residual, recurrent or metastatic GISTs should be treated with imatinib according to the guidelines by European Society for Medical Oncology (ESMO) [54] or National Comprehensive Cancer Network (NCCN) [55]. In this cohort, however, some patients with advanced disease did not undergo IM therapy. Most of the cases were before 2005, when IM was not available in China. In present study, late-stage GIST (residual disease) patients underwent IM therapy had better 3-year OS and 1-year PFS than those who didn't $(75.6 \%$ vs. $6.8 \% ; 87.6 \%$ vs. $12.4 \%$, respectively), confirming the effect of IM on advanced disease.

\section{Conclusions}

In summary, radical surgery is the treatment of choice for operable GISTs. Very low- and low-risk diseases can be treated with surgery alone. Lymph node metastasis is rare in GIST patients and may not be associated with poor prognosis. Large size, high mitotic rate, high risk group, and adjacent organ involvement all contribute to bad outcome of GISTs. IM therapy significantly improves survival of patients with intermediate-high risk or advanced GISTs.

\section{Additional files}

Additional file 1: Univariate analysis of OS. Univariate analysis of overall survival in 401 GIST patients (a: gender; b: tumor size; c: mitotic rate; d: CD34 expression; e: adjacent involvement).

Additional file 2: Univariate analysis of RFS. Univariate analysis of relapse-free survival in 401 GIST patients (a: sex; tumor site; c: tumor size; d: mitotic rate; e: CD34 expression; f: adjacent involvement). 
Additional file 3: Intermediate-high risk GIST. Clinicopathological characteristics of 275 intermediate-high risk GIST patients according to whether received post-operation IM adjuvant therapy.

\section{Abbreviations}

GIST: Gastrointestinal stromal tumor; NIH: National Institutes of Health; IM: Imatinib mesylate; OS: Overall survival; RFS: Relapse-free survival; GI: Gastrointestinal; ICC: Interstitial Cajal cell; PDGFRA: Platelet-derived growth factor receptor alpha; TKI: Tyrosine kinase inhibitor; HPF: High power field; IHCA: Immunohistochemistry assay; SMA: Smooth muscle actin; DOG1: (Discovered On GIST 1); PFS: Progression-free survival; OR: Odds ratio; Cl: Confidence interval; EGIST: Extragastrointestinal stromal tumor; IHC: Immunohistochemical; LNM: Lymph node metastasis; ESMO: European society for medical oncology; NCCN: National comprehensive cancer network.

\section{Competing interests}

The authors declare that they have no competing interests.

\section{Authors' contributions}

The work presented here was carried out in collaboration between all authors. HC conceived of the study, and participated in its design and coordination and helped to draft the manuscript. YYS and QL carried out the IHCA and were in charge of the pathological diagnosis of GIST. LT, WQQ, and CJW were in charge of data collection and follow-up, MW, JX, and YZ analyzed the data. MW interpreted the results and drafted the manuscript. All authors read and approved the final manuscript.

\section{Acknowledgment}

This study was supported by the grant of 1) National Science Foundation of China (no. 81272743) and 2) Projects of Shanghai Committee of Science and Technology (no. 11411950800, no. 13411950902, and no. 13XD1402500).

\section{Author details}

'Department of General Surgery, Ren Ji Hospital, School of Medicine, Shanghai Jiao Tong University, Floor 11, Building 7, NO. 1630, Dongfang Road, Shanghai 200127, China. '2Department of Pathology, Ren Ji Hospital, School of Medicine, Shanghai Jiao Tong University, Shanghai, China.

Received: 20 January 2014 Accepted: 16 September 2014 Published: 18 November 2014

\section{References}

1. Miettinen M, Lasota J: Histopathology of gastrointestinal stromal tumor. J Surg Oncol 2011, 104:865-873.

2. Mazur MT, Clark HB: Gastric stromal tumors. Reappraisal of histogenesis. Am J Surg Pathol 1983, 7:507-519.

3. Miettinen M, Lasota J: Gastrointestinal stromal tumors: review on morphology, molecular pathology, prognosis, and differential diagnosis. Arch Pathol Lab Med 2006, 130:1466-1478.

4. Fletcher CD, Berman JJ, Corless C, Gorstein F, Lasota J, Longley BJ, Miettinen M, O'Leary TJ, Remotti H, Rubin BP, Shmookler B, Sobin LH, Weiss SW: Diagnosis of gastrointestinal stromal tumors: A consensus approach. Hum Pathol 2002, 33:459-465.

5. Dei Tos AP: The reappraisal of gastrointestinal stromal tumors: from Stout to the KIT revolution. Virchows Arc 2003, 442:421-428.

6. Grotz TE, Donohue JH: Surveillance strategies for gastrointestinal stromal tumors. J Surg Oncol 2011, 104:921-927.

7. Joensuu H: Risk stratification of patients diagnosed with gastrointestinal stromal tumor. Hum Pathol 2008, 39:1411-1419.

8. Dematteo RP, Gold JS, Saran L, Gönen M, Liau KH, Maki RG, Singer S, Besmer P, Brennan MF, Antonescu CR: Tumor mitotic rate, size, and location independently predict recurrence after resection of primary gastrointestinal stromal tumor (GIST). Cancer 2008, 112:608-615.

9. Franquemont DW: Differentiation and risk assessment of gastrointestinal stromal tumors. Am J Clin Pathol 1995, 103:41-47.

10. Rossi S, Miceli R, Messerini L, Bearzi I, Mazzoleni G, Capella C, Arrigoni G, Sonzogni A, Sidoni A, Toffolatti L, Laurino L, Mariani L, Vinaccia V, Gnocchi C, Gronchi A, Casali PG, Dei Tos AP: Natural history of imatinib-naive GISTs: a retrospective analysis of 929 cases with long-term follow-up and development of a survival nomogram based on mitotic index and size as continuous variables. Am J Surg Pathol 2011, 35:1646-1656.

11. DeMatteo RP, Lewis JJ, Leung D, Mudan SS, Woodruff JM, Brennan MF: Two hundred gastrointestinal stromal tumors: recurrence patterns and prognostic factors for survival. Ann Surg 2000, 231:51-58.

12. Rosa F, Alfieri S, Tortorelli AP, Di Miceli D, Papa V, Ricci R, Doglietto GB: Gastrointestinal stromal tumors: prognostic factors and therapeutic implications. Tumori 2012, 98:351-356.

13. Dematteo RP, Heinrich MC, El-Rifai WM, Demetri G: Clinical management of gastrointestinal stromal tumors: before and after STI-571. Hum Pathol 2002, 33:466-477.

14. Casali PG, Fumagalli $E$, Gronchi A: Adjuvant therapy of gastrointestinal stromal tumors (GIST). Curr Treat Options Oncol 2012, 13:277-284.

15. Goettsch WG, Bos SD, Breekveldt-Postma N, Casparie M, Herings RM, Hogendoorn PC: Incidence of gastrointestinal stromal tumours is underestimated: results of a nation-wide study. Eur J Cancer 2005, 4:2868-2872.

16. Tryggvason G, Gislason HG, Magnusson MK, Jónasson JG: Gastrointestinal stromal tumors in Iceland, 1990-2003: the icelandic GIST study, a population-based incidence and pathologic risk stratification study. Int J Cancer 2005, 117:289-293.

17. Sandvik OM, Soreide K, Kvaloy JT, Gudlaugsson E, Søreide JA: Epidemiology of gastrointestinal stromal tumours: single-institution experience and clinical presentation over three decades. Cancer Epidemiol 2011, 35:515-520.

18. Pisters PW, Blanke CD, von Mehren M, Picus J, Sirulnik A, Stealey E, Trent JC, reGISTry Steering Committee: A USA registry of gastrointestinal stromal tumor patients: changes in practice over time and differences between community and academic practices. Ann Oncol 2011, 22:2523-2529.

19. Kawanowa K, Sakuma Y, Sakurai S, Hishima T, Iwasaki Y, Saito K, Hosoya Y, Nakajima T, Funata N: High incidence of microscopic gastrointestinal stromal tumors in the stomach. Hum Pathol 2006, 37:1527-1535.

20. Rossi S, Gasparotto D, Toffolatti L, Pastrello C, Gallina G, Marzotto A, Sartor C, Barbareschi M, Cantaloni C, Messerini L, Bearzi I, Arrigoni G, Mazzoleni G, Fletcher JA, Casali PG, Talamini R, Maestro R, Dei Tos AP: Molecular and clinicopathologic characterization of gastrointestinal stromal tumors (GISTs) of small size. Am J Surg Pathol 2010, 34:1480-1491.

21. Wang M, Xu J, Zhao W, Tu L, Qiu W, Wang C, Shen Y, Liu Q, Cao H: Prognostic value of mutational characteristics in gastrointestinal stromal tumors: a single-center experience in 275 cases. Med Oncol 2014, 31:819.

22. Joensuu H, Fletcher C, Dimitrijevic S, Silberman S, Roberts P, Demetri G: Management of malignant gastrointestinal stromal tumours. Lancet Oncol 2002, 3:655-664.

23. Abraham SC, Krasinskas AM, Hofstetter WL, Swisher SG, Wu TT: "Seedling" mesenchymal tumors (gastrointestinal stromal tumors and leiomyomas) are common incidental tumors of the esophagogastric junction. Am J Surg Pathol 2007, 31:1629-1635.

24. Agaimy A, Wünsch PH, Hofstaedter F, Blaszyk H, Rümmele P, Gaumann A, Dietmaier W, Hartmann A: Minute gastric sclerosing stromal tumors (GIST tumorlets) are common in adults and frequently show c-KIT mutations. Am J Surg Pathol 2007, 31:113-120.

25. Alvarado-Cabrero I, Vázquez G, Sierra Santiesteban Fl, Hernández-Hernández DM Pompa AZ: Clinicopathologic study of 275 cases of gastrointestinal stromal tumors: the experience at 3 large medical centers in Mexico. Ann Diagn Pathol 2007, 11:39-45.

26. Mucciarini C, Rossi G, Bertolini F, Valli R, Cirilli C, Rashid I, Marcheselli L, Luppi G, Federico M: Incidence and clinicopathologic features of gastrointestinal stromal tumors. A population-based study. BMC Cancer 2007, 7:230.

27. Bülbül Doğusoy G, Turkish GIST Working Group: Gastrointestinal stromal tumors: A multicenter study of 1160 Turkish cases. Turk J Gastroenterol 2012, 23:203-211.

28. Brady-West D, Blake G: Clinicopathological features and outcome of gastrointestinal stromal tumors in an Afro-Caribbean population. J Nat/ Med Assoc 2012, 104:72-77.

29. Bhalgami R, Manish K, Patil P, Mehta S, Mohandas KM: Clinicopathological study of 113 gastrointestinal stromal tumors. Indian J Gastroenterol 2013, 32:22-27.

30. Caterino S, Lorenzon L, Petrucciani N, lannicelli E, Pilozzi E, Romiti A, Cavallini M, Ziparo V: Gastrointestinal stromal tumors: correlation between symptoms at presentation, tumor location and prognostic factors in 47 consecutive patients. World J Surg Oncol 2011, 9:13. 
31. Kapoor R, Khosla D, Kumar P, Kumar N, Bera A: Five-year follow up of patients with gastrointestinal stromal tumor: Recurrence-free survival by risk group. Asia Pac J Clin Oncol 2013, 9:40-46.

32. Steigen SE, Eide TJ: Gastrointestinal stromal tumors (GISTs): a review. APMIS 2009, 117:73-86.

33. Wong NA: Gastrointestinal stromal tumours-an update for histopathologists. Histopathology 2011, 59:807-821.

34. Gong N, Wong CS, Chu YC: Is lymph node metastasis a common feature of gastrointestinal stromal tumor? PET/CT correlation. Clin Nud Med 2011, 36:678-682.

35. Tashiro T, Hasegawa T, Omatsu M, Sekine S, Shimoda T, Katai H: Gastrointestinal stromal tumour of the stomach showing lymph node metastases. Histopathology 2005, 47:438-439.

36. Sato T, Kanda T, Nishikura K, Hirota S, Hashimoto K, Nahagawa S, Ohashi M, Hatakeyama K: Two cases of gastrointestinal stromal tumor of the stomach with lymph node metastasis. Hepatogastroenterology 2007, 54:1057-1060

37. Agaimy $\mathrm{A}$, Wünsch $\mathrm{PH}$ : Lymph node metastasis in gastrointestinal stromal tumours (GIST) occurs preferentially in young patients $<$ or $=40$ years: an overview based on our case material and the literature. Langenbecks Arch Surg 2009, 394:375-381.

38. Hou YY, Lu SH, Zhou Y, Xu JF, Ji Y, Hou J, Qi WD, Shi Y, Tan YS, Zhu XZ: Predictive values of clinical and pathological parameters for malignancy of gastrointestinal stromal tumors. Histol Histopathol 2009, 24:737-747.

39. Tokunaga M, Ohyama S, Hiki N, Fukunaga T, Yamamoto N, Yamaguchi T: Incidence and prognostic value of lymph node metastasis on c-Kit-positive gastrointestinal stromal tumors of the stomach. Hepatogastroenterology 2011, 58:1224-1228.

40. Brabec P, Sufliarsky J, Linke Z, Plank L, Mrhalova M, Pavlik T, Klimes D, Gregor J: A whole population study of gastrointestinal stromal tumors in the Czech Republic and Slovakia. Neoplasma 2009, 56:459-464.

41. Tanimine N, Tanabe K, Suzuki T, Tokumoto N, Ohdan H: Prognostic criteria in patients with gastrointestinal stromal tumors: a single center experience retrospective analysis. World J Surg Oncol 2012, 10:43.

42. Seker M, Sevinc A, Yildiz R, Cihan S, Kaplan MA, Gokdurnali A, Dane F, Yaman E, Karaca H, Colak D, Uyeturk U, Bilici A, Ozdemir NY, Kalender ME, Uncu D, Salepci T, Isikdogan A, Benekli M, Ozkan M, Gumus M, Coskun U, Camci C, Oksuzoglu B, Buyukberber S, Anatolian Society of Medical Oncology (ASMO): Prognostic factors in gastrointestinal stromal tumors: multicenter experience of 333 cases from Turkey. Hepatogastroenterology 2012, 60:768-775.

43. Chan KH, Chan CW, Chow WH, Kwan WK, Kong CK, Mak KF, Leung MY, Lau LK: Gastrointestinal stromal tumors in a cohort of Chinese patients in Hong Kong. World J Gastroenterol 2006, 12:2223-2228.

44. Agaimy A: Gastrointestinal stromal tumors (GIST) from risk stratification systems to the new TNM proposal: more questions than answers? A review emphasizing the need for a standardized GIST reporting. Int J Clin Exp Pathol 2010, 3:461-471.

45. Coccolini F, Catena F, Ansaloni L, Pinna AD: Gastrointestinal stromal tumor and mitosis, pay attention. World J Gastroenterol 2012, 18:587-588.

46. Joensuu H, Vehtari A, Riihimäki J, Nishida T, Steigen SE, Brabec P, Plank L, Nilsson B, Cirilli C, Braconi C, Bordoni A, Magnusson MK, Linke Z, Sufliarsky J, Federico M, Jonasson JG, Dei Tos AP, Rutkowski P: Risk of recurrence of gastrointestinal stromal tumour after surgery: an analysis of pooled population-based cohorts. Lancet Oncol 2012, 13:265-274.

47. Mrowiec S, Jabłońska B, Liszka L, Pająk J, Leidgens M, Szydło R, Sandecka A, Lampe P: Prognostic factors for survival post surgery for patients with gastrointestinal stromal tumors. Eur Surg Res 2012, 48:3-9.

48. Cho MY, Sohn JH, Kim JM, Kim KM, Park YS, Kim WH, Jung JS, Jung ES, Jin SY, Kang DY, Park JB, Park HS, Choi YD, Sung SH, Kim YB, Kim H, Bae YK, Kang M, Chang HJ, Chae YS, Lee HE, Park do Y, Lee YS, Kang YK, Kim HK, Chang HK, Hong SW, Choi YH, Shin O, Gu M, et al: Current trends in the epidemiological and pathological characteristics of gastrointestinal stromal tumors in Korea, 2003-2004. J Korean Med Sci 2010, 25:853-862.

49. Cao H, Zhang Y, Wang M, Shen DP, Sheng ZY, Ni XZ, Wu ZY, Liu Q, Shen $Y Y$, Song $Y Y$ : Prognostic analysis of patients with gastrointestinal stromal tumors: a single unit experience with surgical treatment of primary disease. Chin Med J (Engl) 2010, 123:131-136.

50. Song Z, Wang JL, Pan YL, Tao DY, Gan MF, Huang KE: Survival and prognostic factors analysis in surgically resected gastrointestinal stromal tumor patients. Hepatogastroenterology 2009, 56:149-153.
51. Fujimoto Y, Nakanishi Y, Yoshimura K, Shimoda T: Clinicopathologic study of primary malignant gastrointestinal stromal tumor of the stomach, with special reference to prognostic factors: analysis of results in 140 surgically resected patients. Gastric Cancer 2003, 6:39-48.

52. Dematteo RP, Ballman KV, Antonescu CR, Maki RG, Pisters PW, Demetri GD, Blackstein ME, Blanke CD, von Mehren M, Brennan MF, Patel S, McCarter MD, Polikoff JA, Tan BR, Owzar K, American College of Surgeons Oncology Group (ACOSOG) Intergroup Adjuvant GIST Study Team: Adjuvant imatinib mesylate after resection of localised, primary gastrointestinal stromal tumour: a randomised, double-blind, placebo-controlled trial. Lancet 2009, 373:1097-1104.

53. Joensuu H, Eriksson M, Sundby Hall K, Hartmann JT, Pink D, Schütte J, Ramadori G, Hohenberger P, Duyster J, Al-Batran SE, Schlemmer M, Bauer S, Wardelmann E, Sarlomo-Rikala M, Nilsson B, Sihto H, Monge OR, Bono P, Kallio R, Vehtari A, Leinonen M, Alvegard T, Reichardt P: One vs three years of adjuvant imatinib for operable gastrointestinal stromal tumor: a randomized trial. JAMA 2012, 307:1265-1272.

54. ESMO / European Sarcoma Network Working Group: Gastrointestinal stromal tumors: ESMO Clinical Practice Guidelines for diagnosis, treatment and follow-up. Ann Oncol 2012, 23(Suppl 7):49-55.

55. von Mehren M, Benjamin RS, Bui MM, Casper ES, Conrad EU 3rd, DeLaney TF, Ganjoo KN, George S, Gonzalez R, Heslin MJ, Kane JM 3rd, Mayerson J, McGarry SV, Meyer C, O'Donnell R, Paz B, Pfeifer JD, Pollock RE, Randall RL, Riedel RF, Schuetze S, Schupak KD, Schwartz HS, Shankar S, Van Tine BA, Wayne J, Sundar H, McMillian NR: Soft tissue sarcoma, version 2.2012: featured updates to the NCCN guidelines. J Natl Compr Canc Netw 2012, 10:951-960

doi:10.1186/1471-2482-14-93

Cite this article as: Wang et al.: Gastrointestinal stromal tumor: 15-years' experience in a single center. BMC Surgery 2014 14:93.

\section{Submit your next manuscript to BioMed Central and take full advantage of:}

- Convenient online submission

- Thorough peer review

- No space constraints or color figure charges

- Immediate publication on acceptance

- Inclusion in PubMed, CAS, Scopus and Google Scholar

- Research which is freely available for redistribution

Submit your manuscript at www.biomedcentral.com/submit
C Biomed Central 